\title{
'SECULAR SACREDNESS' IN THE RITUAL THEATRE OF \\ NICOLÁS NÚÑEZ ${ }^{28}$ \\ Deborah Middleton
}

\begin{abstract}
Núñez has forged a theatre that attempts to provide an active arena for those individuals who seek personal individuation, communitas, or the experience of the sacred dimension in their everyday lives. The TRW carves out a sacred space in the context of an urban cultural institution (p. 155 above; Middleton 2001: 43).
\end{abstract}

The work of Nicolás Núñez and his collaborators at the Taller de Investigación Teatral (Theatre Research Workshop/TRW) in Mexico City offers an activity that responds to both ritual and theatrical imperatives and that integrates religious sources as transferable psychophysical practices. Núñez calls this an 'anthropocosmic theatre', a theatre of 'high risk' for the purposes of personal transformation (See pp. 267 - 287 below; Núñez 2007). He locates the work within a pan-cultural 'secular sacredness', which seeks to reconnect theatre with its archaic ritual sources.

I first began researching Núñez's work in 1993, after encountering his training 'dynamics' at a conference on Performance, Ritual and Shamanism at the Centre for Performance Research in Wales. The article 'At Play in the Cosmos', quoted above, was the result of eight years of engagement in Núñez's work, in residencies that I organized in the UK and during research trips to Mexico. In that period, and since, I have had open access to workshops, daily training, rehearsals, planning meetings and performances. There has been ample opportunity for formal interviews and long informal conversations with Núñez and his collaborators. My role in the work has been that of participant-observer, attempting to maintain that careful line between immersion in experience and the critical distance of the scholarly engagement.

28 Originally published in Performance Research, 2008, 13:3, pp. $41-54$ (https://www.performanceresearch.org/). 
In 'At Play'I was interested in framing Núñez's practice as a ritual activity, elucidated by recourse to ritual structures and concepts and defined by an imperative towards sacrality. In this paper I have explored bases for an understanding of the psychophysical causes and effects of sacred experience within the practice. This paper arises out of my deepened experience; I am now in the second half of my second decade in the work, a chapter characterized by, among other things, periods of immersion in the dynamic Citlalmina (since in 2000, Núñez authorized me to practice the form independently). This writing is informed by my phenomenological experience of the work over time, but for reasons of academic distance, I have preferred to draw directly on the experience of other participants as illustration and evidence.

Núñez's project, and indeed my own engagement with it, are essentially intercultural explorations. While I acknowledge the ethical questions surrounding that aspect of the work, the focus in this article will be on the ways in which such a theatre functions as 'a sacred space'. By identifying the culturally syncretic context in which Núñez lives and works, I hope to provide a perspective which both normalizes and legitimizes the intercultural aspects of his project.

Furthermore, I will approach Núñez's religious sources, as he does, as performance practices that embody pre-cultural frameworks that may be uncovered to produce sets of transferable principles and psychophysical technologies.

To this end, I will explore religious experience per se through a consideration of the consciousness-states and structures involved. Through ascertaining the bodily correlates and mental factors that are found to be instrumental in producing religious - or 'altered' - states (and structures) of consciousness, I will propose a model for producing - or increasing access to - culturally 'unformed' psychophysical experience. Against this framework of ideas, I will map the phenomenological experiences of participants in Núñez's practice, asking to what extent they might be termed 'religious' or 'spiritual' experiences and under what special conditions this aspect of the work flourishes. 


\section{A Mestizo Theatre}

Núñez's project, since founding the TRW under the auspices of the National Autonomous University in Mexico in 1975, has been to create a theatre for contemporary Mexicans - a mestizo theatre, which draws on indigenous as well as European cultural heritages and which reflects the ancient anthropocosmic impulses of the Toltec-Mayan people. Indeed, Núñez calls his an 'Anthropocosmic Theatre'. It takes the form of a series of participatory 'dynamics', used independently as a kind of training and embedded in theatrical devices and structures as a ritual theatre. ${ }^{29}$

The legitimate theatre in Mexico has long been dominated by European influences. At the same time, pre-Colombian ritual performances have survived among the many indigenous peoples of Mexico, often doing so through processes of acculturation. The TRW's imperative has been to create a Mexican theatre which reflects the cultural background of the majority of the population (mestizo) by combining European and indigenous Mexican cultural forms. To this end Núnez has intensively explored such ritual sources as the Nahuatl conchero dance tradition, Huichol shamanic (mara'akame) practices, psychophysical energetic positions derived from phenomenological research into the ancient practices suggested by archaeological artefacts, and imagery derived from the rich pre-Colombian mythologies, notably that of the culture hero, Quetzalcóatl.

This is a complex set of cultural sources; Núñez navigates a terrain characterized by religious and cultural syncretism. Indeed, Timothy Light, a scholar of Comparative Religion, considers that Mexico's national symbol, The Virgin of Guadalupe, is 'as epitomizing an example of syncretism as can be found' (2004: 334). This national symbol, who is both Mary and the Nahuatl fertility goddess or Nature symbol, Tonantzin, is appropriate in a

29 Here, we will be concerned mainly with the activities that fall within the training sphere of Núñez's work, the 'dynamics', and will not address the further problem of whether individuals encountering the work only through a single experience of a ritual theatre production might also have heightened access to what might be identified as the 'religious' form of an altered state of consciousness. 
country where pre-Colombian and colonial religious and cultural forms are intricately interwoven. Widespread cultural syncretism is a lived reality for contemporary Mexicans. The conchero dance tradition, so central to the TRW experience, is, like Maria-Tonantzin, ${ }^{30}$ a tight knit of pre-Hispanic Nahuatl performance and Spanish Catholicism.

It is beyond the scope of this essay to explore the politics of colonial hegemonies, cultural adaptations and resistances. I would, however, like to identify religious syncretism as a context for the work of the TRW. For, as we shall see, Núñez and his collaborators have embraced that tolerance for synthesis and extended it to religious practices from beyond their own mixed cultural heritage.

The TRW might be described as a kind of theatre/anthropological investigation, in Barba's sense (1991), in which attention is focused on the fundamental performative technologies within the sources, eliminating all contexts but the psychophysical. ${ }^{31}$ This essay seeks to understand to what extent religious practices can be stripped down in this way, and represented as theatrical devices which are, nevertheless, designed to cultivate a wholly secular spiritual experience. I have previously claimed that 'Núñez is particularly careful not to invest the actions and experiences of the dynamics with any overt ideology. The TRW professes no particular belief system' (p. 155 above; Middleton 2001: 43). This has been challenged by Antonio Prieto Stambaugh, who responded,

While Taller members indeed avoid imposing a religion or an ideology on participants, there's a particular corpus of beliefs underlying their work. The TRW is intimately associated with a movement of spiritual nationalism known as Nueva Mexicanidad (New Mexicanity), which spans everything from Carlos Castenada to conchero dancing... One of the main leaders of this movement is Antonio Velasco Piña, who is cited in the TRW's playbills as a key advisor (2002: 8).

30 In 1998, five members of the TRW, working under the direction of long-term member Ana Luisa Solís Gil, created the dynamic 'Tonantzin/ Maria'.

31 For a description of two of Núñez's dynamics in these terms, see pp. 157 - 173 above; Middleton 2001: 46 - 56. 
It is true that the TRW engage with both Velasco Piña and the practices mentioned. While I am not aware of Núñez himself having a strong involvement with that movement, some members of Núñez's circle of close collaborators are deeply involved in conchero dancing and other forms associated with the Nuevo Mexicanidad movement. And, as we shall see later, Prieto Stambaugh identifies the work of the TRW as a collective pursuit more than one authored by Núñez himself. Thus he makes a strong connection between the personal orientation of members of the group and the group's practices. In my extensive experience of the TRW's work since 1993, however, I would argue that Núñez's collaborators play a significantly different, though absolutely crucial, role in the development of the dynamics. Núñez, himself, talking about his long-term partner in the work, Helena Guardia, described the relationship thus:

I direct the Taller [Workshop] and its actions. Helena supports and enriches them. I'm responsible for the outside and Helena is a kind of internal catalyser... nothing the Taller has arrived at could have been achieved without her (Núñez 1997:np).

Similarly, the phenomenological reports of collaborators of being inside the work have fed Núñez's research into the precise psychophysical forms, rhythms and meditations that have the potential to create numinous experiences. We will explore below the exact nature of the relationship between belief systems brought to a practice and the fundamental nature and efficacy of the practice itself; between religious experiences that are 'formed' by culture and those that are pre-cultural and 'unformed'.

Núñez appropriates from religious and spiritual contexts only psychophysical practices and anthropocosmic intentions; in the absence of any further instructions or ideological contexts, he offers these to participants as 'theatrical games that will allow ordinary participants to access the realm of the sacred' (p. 159 above; Middleton 2001: 47). If Núñez's collaborators and participants experience the work through personal cultural constructs 
and belief systems, it is Núñez's task to identify the core physiological and cognitive processes that will facilitate the core experiential state itself.

In this way, Núñez has explored and integrated ritual and performance sources from beyond Mexico, notably the Tibetan Buddhist monastic 'Black Hat' dance, which forms one half of the dynamic Citlalmina, alongside a Nahuatl conchero, or shell dance. Núñez uses these sources with the express permission of the Dalai Lama and the leading religious authority from the conchero tradition (pp. 169 - 173 above; Middleton 2001: 54 - 66). In both cases, Núñez learned the forms as they are taught within their respective religious contexts. In creating Citlalmina from these sources, he respected the 'body alphabets', structures and rhythms exactly but abandoned costumes and other artefacts where they did not play an essential role in the psychophysical experience of the form. For example, the vibratory qualities of each dance are preserved; the Nahuatl shell, seed anklets (ayoyotes) and rattles are used in Citlalmina, the bone trumpets of the Black hat dance are replaced by a vibratory vocalization (the sacred syllable $\mathrm{Hu}$ ). Citlalmina is a cornerstone of the TRW's practice. Performed weekly throughout the year in Mexico City and open to participants who range from students of acting to ordinary Mexicans wishing to engage with their cultural heritages, it represents a major vehicle for Núñez's participants to engage in a secular pursuit of sacred experience.

\section{Secular Sacredness}

Before addressing Núñez's practice in any further detail, then, we need to understand the parameters of the term 'secular sacredness'. What is it, first of all, that we refer to when we say 'the sacred'? While recourse to the presence or power of a God is a usual and convenient shortcut, there is something necessarily circuitous in this, since our experience of that which we call 'God' is or is via that which we call the sacred. Within the field of Religious Studies, there are a number of definitions of the sacred: that which is 'wholly other' (Durkheim 1995 [1912]); 'absolute' or 'ultimate' or of the highest (transcendent) value (Eliade 1957); that which inspires 'awe', 
the mysterium tremendum, the 'numinous' (Otto 1923 [1917]); that which conveys a profound sense of the connectedness of an ultimate reality, believed to underlie daily reality (Huxley 1944). These are not exclusive categories but rather differences of emphasis and approach.

For Durkheim, Eliade, Otto, Huxley, and for William James (1960 [1902]), the 'sacred' does not, by necessity, imply a deity, nor is it definitively bound up with the domain of religion (which I take, here, to imply both divinity and organized belief system). Let us, then, look more closely at the key characteristics of the sacred, as experienced and articulated across cultures.

The 'sacred' is inferred [either through lived experiences, or by conceptual processes: ${ }^{32}$

\begin{tabular}{|c|c|}
\hline $\begin{array}{l}\text { by } \\
\text { PHENOMENAL EXPERIENCE } \\
\text { (which suggests } \\
\text { conceptualization) } \rightarrow\end{array}$ & $\begin{array}{l}\text { by } \\
\text { CONCEPTUALIZATION } \\
\text { through contrast with the 'known' }\end{array}$ \\
\hline $\begin{array}{l}\text { of } \\
\text { awe, the numinous, } \\
\text { mysterium tremendum } \\
\downarrow\end{array}$ & $\begin{array}{l}\text { described as } \\
\text { other, absolute, } \\
\text { ultimate, highest } \\
\downarrow\end{array}$ \\
\hline $\begin{array}{l}\text { which conveys experience of } \\
\text { profound connectedness } \\
\downarrow \\
\text { cognized as } \rightarrow\end{array}$ & $\begin{array}{l}\text { characterized by - } \\
\text { unity of all things }\end{array}$ \\
\hline $\begin{array}{l}\text { and equates to } \\
\text { 'being' } \\
\text { in contact with } \rightarrow\end{array}$ & $\begin{array}{l}\text { believed to be } \\
\text { underlying reality }\end{array}$ \\
\hline
\end{tabular}

32 The table has been slightly amended from the original to improve clarity. 
Thus, our sense of the sacred seems to be forged on phenomenal experiences that are of an order 'wholly other' to those of daily - mundane - existence, from which we infer categories relative to that of mundane existence. Those categories are either articulated in qualitative terms, or they imply realities that are, by definition, beyond the range of our conceptual scope. And yet, despite this reaching into a conceptual void, the world's religious, spiritual and transcendentalist literatures represent a surprising coherence. Arthur Deikman, a psychiatrist researching in the field of consciousness and mysticism, states,

Profound connection is what the word 'spiritual' properly refers to... At its most basic, the spiritual is the experience of the connectedness that underlies reality (2000: 84).

The spiritual quest is one that attempts to draw the subject into relation with a sacred realm, in which we experience a connectedness to an underlying reality that is itself one of profound connectedness between all things.

Thus, the 'sacred' represents for us a ground of being that the world of daily, subjective existence cannot provide. For Eliade,

[r] eligious man's desire to live in the sacred is in fact equivalent to his desire to take up his abode in objective reality, not to let himself be paralyzed by the never-ceasing relativity of purely subjective experiences, to live in a real and effective world, and not in an illusion (1957: 28).

As we shall see later, the sacred as objective reality may be understood as an experience brought about by a perceptual shift from a daily mode to one that is not bound by instrumental object-consciousness. From our isolated subjectivity behind veils of perceptual and conceptual consciousness, we are understood to break through to a reality that our daily modes of being can never reach. In that reality, the mystics tell us, the illusion of separateness is destroyed.

For Eliade, 'the sacred is equivalent to a power, and, in the last analysis, to reality. The sacred is saturated with being... religious man deeply desires to be' (Eliade 1957: 12-13). Thus, contact with the sacred infuses us with 
an ontological certainty and energy that is not supported in the mundane world. Our phenomenological being-state is intricately connected to our engagement with an objective Universe. Contact with the sacred releases us from the isolation of a world in which we are doomed to perceive only 'fragments of a shattered universe' (24). For Eliade, the experience of the sacred 'founds the world' and thereby creates 'cosmos' $(23,29)$.

As we know, Núñez identifes his theatre as 'anthropocosmic' - a theatre of the human in the cosmos. Guided by pre-Hispanic mythological sources, Núñez sees a theatre for Mexico as necessarily embracing the ancient practices believed to assist people in 'aligning themselves with the cosmos'. Núñez's professed aspirations are to provide participants with experiences in which they may achieve a sense of connectedness to an underlying reality. Psychophysical experiences, supported by mythological imagery, are designed to act as imaginal 'thresholds' or 'portals' to an experience of reality that will, in Eliade's terms, 'sacralize the cosmos' (Eliade 1957: 17) and increase access to ‘being'. For Núñez, the Actor is a sacred animal, alongside the bull, the deer, etc. The sacrality of the Actor resides within the ability to access heightened states of being in which perception alters, such that we feel that we bypass cognitive conceptualizing and directly encounter the cosmos. Núñez tells us, we have to make clear that the shaman or the actor is someone who, at will, can go into an altered state of consciousness, go in and out at will... $[\mathrm{T}]$ he mind has two main functions; the first one... is to intellectualize or rationalize... the second one is to perceive reality directly with no interference of any kind of thinking, to intuitively catch the reality not what we think it is - see what it is (1993).

The Actor, then, is seen as a hierophant or shaman with the technologies to make a bridge from the 'shattered universe' into the unified ground of being.

In Núñez's work we find an emphasis on the triad of sacrality, being and cosmos, which our sources have identified as the fundamental religious imperatives. How then should we understand an activity such as that of the 
TRW, which divorces anthropocosmic technologies from their religious contexts and espouses a secular sacrality?

In Das Heilige ('The Holy' or 'The Sacred') Rudolf Otto introduced the term 'numinous' to describe the experience of the 'sacred'. His mysterium tremendum is the experience of awe, of overpowering presence and energy, and of enrapturing fascination in the face of that which is 'other'. For Otto, the experience of the sacred is one to which humans are predisposed. That predisposition can find expression in - or be projected onto - the natural world or an imputed supernatural world. Thus, for Otto, the numinous experience is a natural capacity, prior to and not by necessity associated with religion per se. The experience of the sacred - or the impulse to imbue aspects or artefacts of experience with sacred connotations - is not exclusive to the domain of religion (Eliade 1957).

One of the primary functions of religion, however, according to Durkheim, is to create a division between the sacred and the profane. His sense of the sacred is not synonymous with the divine since there are primary forms of worship of the sacred that do not involve divinities, and it was one such (indigenous Australians) on which Durkheim based his explorations. While ultimately Durkheim sees the totem as symbolizing a sacred reality, which is itself a projection of a social reality, it is pertinent to note that the sacred has a fundamentally non-religious connotation for him (1995 [1912, 1915]). William James notes that

$[t]$ here are systems of thought which the world usually calls religious, and yet which do not positively assume a God... the Buddhistic system is atheistic. Modern transcendental idealism, Emersonianism... Not a diety in concreto, not a superhuman person, but the immanent divinity in things, the essentially spiritual structure of the universe, is the object of the transcendentalist cult (1960 [1902]: 50).

'Secular sacredness' might sound, at first hearing, like an oxymoron. Yet the opposite of the sacred is not the secular but the profane. The concept of the 
sacred forms a polarity with the concept of the profane, each defining and delineating the other. It is worth noting, as Eliade does, that the poles do not equate to a positive and negative; each may contain both - the realm of the sacred consists of evil as much as beneficent powers. The secular pertains to that which is not the religious life or order, thus to permit a secular sacrality, we must only allow that the sacred may be found beyond the bounds of that which we determine to be the domain of religion. As our definitions above suggest, we might well expect to experience the absolute, the wholly other, the interconnected universe without an organizing principle in the form of religious structure or belief.

Before we leave our discussion of the parameters of the 'sacred', it is worth noting that for Durkheim the sacred also referred to a context greater than the individual and the mundane - the collective life of the community (1995 $[1912,1915])$. This will be discussed further below, where we shall see the biological benefits accruing to a practice of service to the community, and shall relate this to the group-basis of Núñez's practice and to the development through that of communitas.

\section{Experiences in Consciousness}

We have then, a definition of the sacred that allows for secular contexts and emphasizes modes of ontological being, phenomenological states of perceiving and of cognizing the cosmos in which we exist. Experience of the sacred, then, may be seen as an experience in consciousness. Indeed, there is an emergent field of study of precisely this - the consciousness of religious experience - a field that:

1. gives us a framework for analysis (below)

2. establishes the pre-cultural aspects of spiritual practice and experience, which support Núñez's hypothesis

3. provides an insight into the kinds of methodological research that pertain to analysis of religious experience (and, indeed, to the 
construction of such experiences, and therefore provides a support for Núñez's methodology).

For Andresen and Forman, editors of 'Cognitive Maps and Spiritual Models' (a themed edition of the Journal of Consciousness Studies), religious and spiritual experiences may be seen 'not solely as cultural phenomena but as phenomena that can be related to human physiology, and a kind of panhuman technology of human spiritual development'(2000: 7). Consciousness studies allow for neurological and phenomenological perspectives on the modes of being and states of experience that we associate with the sacred. It is these perspectives that better allow us to understand the complex interplay of culture and biology in the emergence of religious states. '[C]onsciousness' stands as the mediating term between the qualia, or felt experience, of the subjective, and the 'hard' reality we refer to as 'the external world' (8).

Andresen and Forman point out that causal vectors move in both directions between consciousness and culture. Cultural constructs including language influence our ability to have specific experiences, but individual subjective experiences also shape culture: 'Culture and consciousness interact with, and reflectively influence, one another, and so do biology and consciousness' (9). This essay will assume both the viability (indeed necessity) of a methodology that incorporates subjective experience and the primacy of measurable physiological and psychological factors within even the most mystical of religious states.

For Perennial psychologists, mystical experiences of sacred reality across cultures 'share certain common underlying experiential cores'. Andresen and Forman specifically identify those instances as 'non-dualistic', as 'largely, or perhaps even entirely, unconstructed by cultural language and background' and as 'unformed' $(8,12)$.

The emerging picture of religious experience is of 'a particular kind of consciousness' which possibly 'reflects pan-human correlations at a deeper level than conceptuality - electrical activity in the frontal and temporal lobes of the brain, the stimulation of hormone flows and the ceasing of random 
thought-generation all may be seen as cross-cultural technologies of spiritual experience' (13). At a physiological level, these are 'unformed' states, but how these states are experienced, conceptualized and articulated will largely be shaped by culture and language.

We might, then, understand mystical and shamanic ritual practices as 'technologies' of mental and energetic means by which to generate 'religious' or cosmological consciousness. These are Eliade's 'technologies of the sacred', which Stanley Krippner identifies as 'a group of techniques by which practitioners deliberately alter or heighten their conscious awareness' (Krippner 2000: 98).

Núñez's cross-cultural researches have explored precisely this terrain, as a result of which the 'tools' of the TRW are a set of psychophysical techniques that can be combined in different ways, and with different mythological imageries, to create the interactive 'dynamics'. The 'tools' include: slow walking, whirling, 'contemplative running', corporeal alphabets and energetic positions. The dynamics are constructed around four fundamental principles, also derived from the research sources: continuous movement; continuous mental focus on one's experience; changing, specific rhythms; alternation between tension and relaxation. The intricate interplay of mental and physical strategies in the dynamics is such that we can describe them as techniques of 'meditation in movement' (pp. 157 - 173 above; Middleton 2001: 46-56).

\section{From the Profane to the Sacred}

Arthur Deikman's analysis of mystical technique delineates three useful polarities within which we can locate Núñez's practice:

Instrumental consciousness - Receptive consciousness

Object consciousness - Unboundaried sense of self

Survival self - Spiritual Self

These in turn highlight three important factors for consideration: intention, attention and perceptual deautomatization (2000: 75-99). Deikman tells us that 
there are different modes of consciousness to serve our basic intentions - they are functional. To act on the world requires a sharp discrimination between self and others and between self and objects... an acute sense of linear time is needed... In contrast, to take in, to receive from the world calls for a different mode of consciousness, one in which boundaries are more diffuse, the Now is dominant, and thought gives way to sensation (79-80).

Deikman points out that normal human cognitive maturation involves the development of capacities for object-recognition, boundary-perception and conceptualization. These capacities and their related skills (with regard to space, time, causality and self) become automatic in normal childhood development. Meditative and mystical practice involves, in Deikman's analysis, a deautomatization:

The meditation activity that my subjects performed was the reverse of the developmental process: the percept... was invested with attention while thought was inhibited. As a consequence, sensuousness, merging of boundaries and sensory modalities became prominent. A deautomatization had occurred (77).

Deikman's meditators were intentionally shifting their consciousness from a daily mode, which has evolved for instrumental and survival purposes, to a 'spiritual' mode of receptivity. The mental apparatus of instrumental consciousness itself creates a 'barrier to experiencing the connectedness of reality'. In contrast, a shift to a receptive mode of being enables both perception and experience to shift also. Deikman identifies that this is fundamentally 'a shift in intention away from controlling and acquiring and toward acceptance and observation. The emphasis is on taking in instead of acting upon' (78-80).

The elements identified by Deikman are common to many meditational practices: focused attention upon a percept, the intention to accept and observe [which in turn implies a cessation of ego-activity], the quietening of conceptualization, the dilation of sensory and perceptual activity. In 
Núñez's dynamics, attention is focused in the moment-by-moment somatic experience through intentionality, breathing technique or use of mantra. Receptive consciousness is engaged through the necessity to remain within long-durational activities, abandoning end-gaining strategies and timeconsciousness. Conceptual activity is subdued, partly through intention, and partly through the psychophysically strenuous tools of running, energetic position etc. Energies are dilated through physiological effects (such as adrenalin and endocrine release), and this in turn intensifies the somatic nature of the experience. Deikman has already identified the perceptual deautomatization involved in the shift from one mode of consciousness to another. In Núñez's dynamics we also find a complementary deprogramming on the physical plane. Many of the dynamics involve physically counterintuitive actions, such as running backwards with eyes closed, or some of the complex turns in Citlalmina. This, too, helps the participant to remain in a state of alertness and presence, vigilant to the necessity to maintain a nonhabitual attentional energy.

These, then, are psychophysical structures with the potential to facilitate a meditator's refusal of ordinary consciousness, with its inherent limitations and filtering constructs, in favour of what Deikman calls 'a mode of consciousness responsive to [reality's] connected aspects' (89). Or, rather, a mode of consciousness that does not, by nature of its developmental apparatus, prevent the experience of objectless, unboundaried connection.

It seems, then, that we may access what we are calling 'religious' states of consciousness, in which to experience cosmos, simply by utilising technologies of mind and body. We must be mindful, however, that those states will be experienced and conceptualized in ways that depend upon the cultural and language backgrounds of the subjects. Karoliina Sandström, who has for two years been participating in the experiences of Citlalmina, which I run at the University of Huddersfield, writes:

So for me there exists a quest for 'being' in the universe, which I will approach from a particular individual and societal stance. Even though 
each individual's understanding of 'being' differs, the practice of, for example, Citlalmina, facilitates a group participation in which there is the possibility of such a quest taking place. And for me this quest for 'being' (or warriorship) can in some degree transcend cultural and societal contexts to allow for possibly very different yet still related spiritual experiences (Middleton 2008).

In 2006, Núnez led a group from the TRW in a 'high-risk theatre' training exercise comprised of ritually walking the camino, or pilgrimage, to Santiago de Compostela in Northern Spain. ${ }^{33}$ Lee Rickwood, an Australian actor who joined the company for that experience and went on to work with them in the subsequent theatre production, Caceria de Estrellas (2007), describes the ways in which the group were facilitated in accessing and understanding the experience as a secular pursuit:

The approach that Nicolás had devised for the group was held together by the image of Quetzalcoatl, the feathered serpent... The major historical 'story' of the Camino is that it is a Christian pilgrimage... Yet walking in the serpent allowed us to have an experience of the Camino outside this dominant narrative, creating our own, shared, secular sacred experience. We were a group joined not by a religious order or set of beliefs, but by our imaginations... and in walking it becomes a psychophysical sacred experience (Middleton 2008).

In Rickwood's analysis, both personal imaginative response to archetype and the psychophysical effects of ritual walking facilitated a numinous experience, which she defined as entirely secular, divorced from the 'dominant narrative' adhering to it. Eilon Morris, who has experience of the dynamics both with Núñez and in my use of them in England, describes his practical strategy for encountering the forms in a way that acknowledges cultural contexts:

33 I joined the TRW halfway through their forty-day pilgrimage to Compostela and, beyond it, to Finisterre on the west coast, a point considered by some to be the end of an ancient pre-Christian pilgrimage into the West. 
My personal experience is that through approaching these forms with humility and respect and an understanding of some of the principles that underlie them, I am able to engage in a personal relationship between myself and the experiences revealed through their practice. This engagement occurs without an in-depth knowledge or personal connection to the cultures that they are drawn from. There is the risk, I am aware, that if the forms are performed purely as physical movements and body positions, they may only function as physical exercise and or dance moves. Therefore I feel there is a need for some form of personal connection and commitment to the work (Middleton 2008).

As with meeting another person, we can have an authentic encounter with a performance form, even across cultural, experiential and linguistic divides, when that encounter is forged in humility, respect and a pre-conceptual level of engagement. Morris's principles, derived from work with Núñez and others and through which he accesses the dynamics, orient him to an approach that reduces the risk of cultural imposition and facilitates receptive consciousness in Deikman's terms. Morris writes:

- a vigilant approach to working with my attention in order to support my intentions in the work

- ongoing search for the living potential within the form

- finding and drawing on a personal inner mantra

- relaxing my vision, allowing it to move freely throughout the work

- listening to the sounds and rhythms of the rattles and the steps and allowing these to work through me, rather than attempting to control them (Middleton 2008).

It is clear that psychophysical forms are constructed not purely from physical actions but from the interplay of those actions with highly specific attitudinal foundations. Núñez's 'meditation in motion' requires the same disciplining of mind as can be found in other forms of sitting or walking meditation. Ultimately, indeed, the interior orientation is the most important element. 


\section{As Deikman explains,}

[a] student can meditate for years focused on breathing sensations but if she is inwardly trying to grasp enlightenment, to possess it, that acquisitive aim will lock her into the same form of consciousness with which she had begun. That is why mystics say that 'the secret protects itself'. No cheating is possible because it is the interior orientation that is critical (2000: 78).

One might say, too, that appropriation of sacred forms through acts of cultural piracy or vandalism are also protected against in this way. It is only when engaging with an authentic interior attitude that a person can be said to be actually performing the form and, indeed, benefiting from it. Otherwise, as Morris suggests, it is simply 'physical exercise'.

The meditative, or spiritual, path is itself a vehicle for moving towards the attitudes of inner orientation that are crucial here. Andresen and Forman describe the ways in which such practices centrally consist of an incremental movement away from culturally formed consciousness to the unformed panhuman levels of mind activity mentioned earlier.

One begins a spiritual practice, of course, utterly enmeshed in the historical world... As meditation slowly moves one away from sensation and thought, the formative role of background and context slowly slip away. One becomes less aware of one's surroundings, thinks with borders that are less and less defined... [I]n some branches of Buddhism and Hinduism, practitioners are believed to have become less and less enmeshed in samsara, the cyclical mundane world (2000: 12).

This, however, brings us to a critical distinction between experiences of altered states of consciousness on the one hand and incremental processes of spiritual development on the other.

\section{States and structures}

According to Ken Wilber's extensive survey of religious experience in Eastern and Western psychological systems, 'a person at virtually any stage or level of 
development can have an altered state or peak experience - including a spiritual experience' (Wilber 2000: 149). When these are developed into 'permanent traits' to which the individual has 'more-or-less continuous and conscious' access, 'these transitory states are converted into permanent structures of consciousness' $(150,154)$. Access to altered states of consciousness appears to be an innate capacity, but the related structures of consciousness, which would enable these states to become permanent traits, must be developed through a staged evolution $(165,153)$. Further, Wilber points out that

the ways in which these altered states will (and can) be experienced depends predominantly on the structures (stages) of consciousness that have developed in the individual (154).

While I have proposed that Núnez's practices meet the criteria for creating conditions for the arising of spiritual states of consciousness, we must now ask whether the work also provides for an ongoing developmental process through which those temporary states could influence the individual's ongoing experience. If a practice facilitates the arousal of states but does not provide a developmental process, what are the implications for that practice as a spiritual vehicle? As a means of providing access to 'secular sacredness'?

For Helena Guardia, Núñez's long-term collaborator in the TRW, these are also central questions:

What's the use of dynamics and practices that take you so energetically to the right side of your brain, that raise your energy so powerfully and make it soar, that open new scopes and give a deeper and more joyful meaning to life, if we do not extend this and produce a real change in our daily affairs. These practices put us in contact with our Being, that place where we can feel that it might be true that we are one with the 'ten thousand things'... If you practice but cannot control your depressive emotions, is it useful? What's the use of ritual if we cannot 'transport' this dimension into our everyday lives, in order to 'transform' them? (Middleton 2008). 
In what ways, then, does the work of the TRW encourage not only immersion in transient being states but the development of those states into altered structures of consciousness? Robert Forman explains that

[the] discriminating feature is a deep shift in epistemological structure: the experienced relationship between the self and one's perceptual objects changes profoundly. In many people this new structure becomes permanent (1998: 186).

Thus, while the wisdom literature of the world records numerous examples of sudden 'Road to Damascus' experiences producing permanent epistemological changes, we might also expect to find long-term repetition of practice, as well as incremental internal processes of engagement. I have previously identified within the TRW's dynamics a series of practical objectives - like a ladder, 'each rung facilitating access to the next. The participant's attainment of each rung is also... the attainment of a level of psychophysical development':

1. silence the rational mind; control the mind's tendency to engage in discursive and instrumental activity

2. be present in the here and now and focus on the somatic sensations of the bodymind

3. focus mental and physical energies and work with raising and controlling energy (p. 163 above; Middleton 2001: 50).

At each of these levels, the participant enters into relationship with aspects of the self (thoughts, feelings, energies), thereby dissolving habitual identification with that aspect and developing the 'observer self' of meditative practice, which enables a profound epistemological shift away from ego-consciousness into the active receptivity that Deikman identified as crucial to the mystical path.

For Núñez, actor training requires an incremental process akin to that of the spiritual path. He writes that

$[t]$ he training tools of a true actor go hand in hand with the training tools of the spiritual warrior... [T] he actor has to train his mind, his speech and his body through discipline, intent, concentration and 
intelligence, exactly as, for example, the Tibetan Shambhala-tradition warrior, or the warrior from the Meso-American Nahuatl tradition... Both are disciplines of spiritual warriors with the same aim of becoming channels for the sacred (Núñez 2000: 21; see also p. 277 below).

Thus it is that the activities of the TRW attract both actors in training and individuals seeking personal and spiritual transformation, both Mexicans making contact with their own cultural heritages and non-Mexicans for whom the work provides structured and accessible experiences at a precultural level.

Theatre is literature and spectacle, play and catharsis, but it is also an initiation ceremony. Núñez and his colleagues have striven to reintroduce the sacred dimension into theatre (Octavio Paz, p. 9 above).

Núñez sees the history of theatre as a development away from ritual efficacy and towards entertainment (See Figure 11 on p. 270; Núñez 2007: 14; see also Schechner 1988: 106-52). He tracks a historical trajectory from early ritual contact with 'pure energy' into the conversion of that energy into deity, and from there into the personified epic culture hero. When the culture hero 'becomes a human being... he performs no more extraordinary feats and now he has emotional conflicts; his rank is theatrical' (Núñez 2000: 11; see also p. 270 below). The history of theatre, for Núñez, is one of descent from the sacred to the profane.

The work of the TRW has been to reinvest contemporary theatre with ritual potentialities and sacred connotations, to move from a foundation in theatrical activity into the realms of the epic and the mythic and from there to the experience of pure energy and cosmos that we associate with archaic rites. In Núñez's analysis, contact with the sacred is the birthright of the theatre, and the actor and hierophant are like twins who share common energetic and imaginal capacities to access other realms of being, other levels of consciousness (2007: 17; see also Figure 12 on p. 272 below). In recent history, Western theatre has aligned itself with commerce and the profane; 
only in some isolated examples (notably that of Grotowski, with whom Núñez trained and worked [Núñez 2000: 51-64]) do we find the Actor using their trained potentials to access cosmos.

And yet, there are ways in which the core characteristics of theatre continue to provide a natural environment for a sacred pursuit. Helena Guardia writes,

It is possible to enter altered states of consciousness through any form of art, all of them take you beyond time and space, as meditation does, but only in theater - as ritual (for it involves participation) - can you share the precise, living instant of soaring, and the mutual commitment deriving from it (Middleton 2008).

As a fundamentally communal art form, theatre provides a space in which one's meditative and energetic training may be supported by a congregationlike body of mutual initiates. This is important in two ways; one, encounter with the 'other' facilitates the pursuit of 'being' mentioned above, and two, the group experience of communitas supports individual effort and equates to what Deikman saw as a biologically adaptive characteristic of spirituality: 'service'.

On the role of the other in ones individual journey, Karoliina Sandström tells us

$[t]$ here is a strong sense of shared experience, which, for me, not only relates strongly to the possibilities of developing one's engagement in performative work, but also suggests another possibility of engagement in the universe... There are times in the work when I feel that the dynamic and the group are helping me to meet myself and the world... I see a strong link between the work and... meeting [another] person... and being present in ones performative practice (Middleton 2008).

Many of the TRW's dynamics place the individual in profound contact with another. In the midst of techniques that shift our identification away from ego-self, meeting another person can represent a rare opportunity for undefended presence - being - which we see reflected in the partner's eyes (p. 175 above; Middleton 2001: 58). Often, the contact with the other involves 
facilitating their experience, as many of the dynamics include tools, such as running backwards with eyes closed, that require the presence of a vigilant partner. The TRW's aim may be to provide rituals of personal transformation, yet the work can never be individualistic or self-centred. One operates within the group as within a theatrical ensemble, fitting ones energies and actions to the group needs and relying on that group, in the long-durational actions, for energetic support. This creates a strong sense of communitas, even among large groups of strangers meeting in the work for the first time.

In dynamics such as Tloque Nabuaque, participants move in repeating rhythmic patterns of coming together and moving apart, in such a way as ultimately to blur one's sense of boundaries and separateness from the other. Lee Rickwood describes her experience:

I moved from a sense of separateness to a sense of connectedness to a sense, midway into the dynamic, of an ongoing interconnectedness, whether in the cluster or moving separately. For me, this experiential interconnectedness was an experience of communitas and sacred space ... energizing, expansive and empowering (Middleton 2008).

As Deikman has noted, mystical practices 'help a person "forget the self", to diminish the extent to which survival needs dominate consciousness' (2000: 83). We have already considered the role of meditation in doing this; Deikman also offers an analysis of the practices of 'renunciation and service', each of which dissolves self-centredness and encourages a receptive mode of being and an experience of interconnectedness. The aim of the TRW is to create experiences in which participants can align themselves with the cosmos, and this is achieved through the cultivation of a strong internal discipline, necessary for 'serving the task' (what Deikman calls 'true service' [85]). It is for good reason that Antonio Prieto Stambaugh draws attention to the 'collective nature of much of the [TRW's] activity' (2002: 7).

With his collaborators in the TRW, Núñez has carried out a phenomenological research across cultures in order to establish the parameters 
and principles of an anthropocosmic theatre. The result is a paradigm forged upon psychophysical practices, which are supported not by religious ideas or doctrines, nor by conceptual ideologies, but rather by technologies of attention and intention, modes of relation to self and other.

\section{REFERENCES}

Andresen, Jensine (2000) 'Methodological Pluralism in the Study of Religion', Journal of Consciousness Studies 7.11-12: 17-73.

Andresen, Jensine and Forman, Robert (2000) 'Methodological Pluralism in the Study of Religion', Journal of Consciousness Studies 7.11-12: 7-14.

Barba, Eugenio (1991) A Dictionary of Theatre Anthropology: The Secret Art of the Performer, London: Routledge.

Deikman, Arthur (2000) 'Methodological Pluralism in the Study of Religion', Journal of Consciousness Studies 7.11-12: 75-91.

Durkheim, Emile ([1912,1915] 1995) The Elementary Forms of Religious Life, New York and London: Free Press.

Eliade, Mircea (1957) The Sacred and the Profane, San Diego, New York and London: Harcourt.

Eliade, Mircea ([1964]1989) Shamanism: Archaic Techniques of Ecstasy, London: Arkana.

Forman, Robert (1998) 'What Does Mysticism Have to Teach Us About Consciousness?' Journal of Consciousness Studies 5.2: 185-201.

Huxley, Aldous (1944) The Perennial Philosophy, New York and London: Harper.

James, William ([1902]1960) The Varieties of Religious Experience, London and Glasgow: Fontana.

Krippner, Stanley (2000) 'Methodological Pluralism in the Study of Religion', Journal of Consciousness Studies 7.11-12: 93-118.

Light, Timothy (2004) 'Orthosyncretism: An Account of Melding in 
Religion' in Anita Maria Leopold and Jeppe Sinding Jensen (eds) Syncretism in Religion, London: Equinoz, pp. 325-47.

Middleton, Deborah (2001) 'At Play in the Cosmos: The Theatre and Ritual of Nicolás Núñez', TDR 45.4: 42-63.

Middleton, Deborah (2008) Unpublished interviews and personal correspondence.

Núñez, Nicolás (1993) Conference address at 'Performance, Ritual and Shamanism', Centre for Performance Research, Cardiff, Wales.

Núñez, Nicolás (1996) Anthropocosmic Theatre: Rite in the Dynamics of Theatre, Amsterdam: Harwood.

Núñez, Nicolás (1997) Personal correspondence with the author.

Núñez, Nicolás (2000) The Flight of Quetzalcoatl, Unpublished pamphlet.

Núñez, Nicolás (2007) Teatro de Alto Riesgo. Mexico City: Consejo Editorial del TIT de la UNAM. Translated by Helena Guardia.

Otto, Rudolf ([1917]1923) The Idea of the Holy, trans. John W. Harvey, London: Oxford University Press.

Prieto Stambaugh, Antonio (2002) 'To the Editor', TDR 46.3: 7-8.

Schechner, Richard (1988) Performance Theory, New York: Routledge.

Stewart, Charles and Shaw, Rosalind (1994) Syncretism/Anti-Syncretism, Oxon: Routledge.

Wilber, Ken (2000) 'Methodological Pluralism in the Study of Religion', Journal of Consciousness Studies 7.11-12: 145-76. 